\title{
Risk counselling in autosomal dominant disorders with undetermined penetrance
}

\author{
RICHARD M PAULI* AND ARNO G MOTULSKY \\ From the Departments of Medicine and Pediatrics, and the Center for Inherited Diseases, University of \\ Washington, Seattle, Washington 98195, USA
}

SUMMARY A method is presented for estimating the probability of an affected child being born to a $\vec{\infty}$ clinically unaffected subject who is at risk for having inherited a rare gene for an autosomal dominant disorder of unknown penetrance. The maximal risk is $8.6 \%$ for children of persons at $50 \%$ risk for having inherited the mutant gene regardless of the true penetrance of the disorder in question. Applications of this maximal risk figure, which should be of benefit in various counselling situations, are summarised.

Genetic counsellors often face situations in which precise risk figures are unavailable. An example of such an occasion is establishing the risk for a clinically affected offspring to be born to an unaffected subject at risk for having inherited a gene for a rare autosomal dominant condition of unknown penetrance. In calculating the worst possible risk for such a subject, we were struck by the relatively low risk values found, regardless of penetrance. Since the derived risks are applicable in various counselling situations, the results appear to be of general interest to genetic counsellors.

\section{The genetic counselling problem}

A woman (III.5, fig 1) sought counselling for her risk of having a child with split foot/split hand syndrome (SF/SH), a recognised autosomal dominant disorder with reduced penetrance. ${ }^{1} \mathrm{Her}$ sister (III.2) and nephew (IV.1) had been previously examined by us and found to have typical SF/SH deformity compatible with the autosomal dominant form. Clinical and radiological examination of the proband and her husband revealed no abnormalities related to SF/SH syndrome. However, a distant relative of the proband (II.12) has a congenital unilateral hand and forearm abnormality including absence of the second, third, and fourth fingers. While this malformation could be coincidental, the infrequency of such a hand defect and its presence in a

*Present address: Departments of Pediatrics and Genetics, University of Wisconsin, Madison, Wisconsin 53796, USA.

Received for publication 15 October 1980

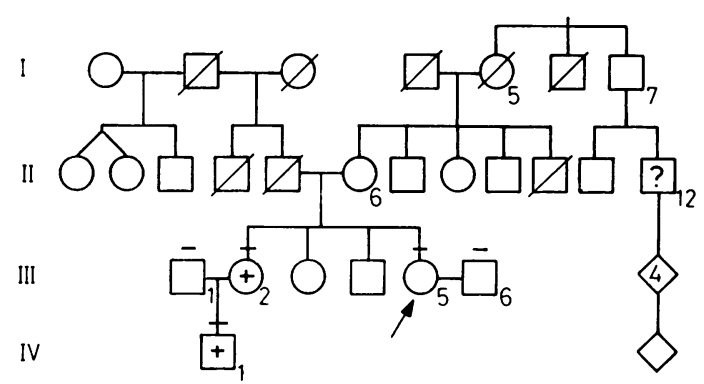

FIG 1 Pedigree of the reported family. The proband is indicated with an arrow. $+=$ subjects clearly affected with split foot/split hand syndrome.? = subjects with hand and arm abnormalities possibly related to split foot/split hand syndrome. A horizontal bar over the pedigree symbol indicates that the subject was personally examined.

kindred with $\mathrm{SF} / \mathrm{SH}$ syndrome suggest that it may $\frac{T}{0}$ be related to the SF/SH in other family members. In view of the autosomal dominant inheritance and $N$ incomplete penetrance of $\mathrm{SF} / \mathrm{SH}$ syndrome, ${ }^{1-3}$ it is $\mathrm{N}$ possible that various clinically unaffected relatives $N$ (II.6, I.5, I.7) carried the gene. Calculations based on $\omega$ these assumptions represent the worst possible risk for our consultand having a clinically affected child. $\stackrel{\circ}{\leftarrow}$

\section{Derivation}

Bayesian methods can be used to estimate the risk of $\frac{\mathrm{O}}{\mathrm{D}}$ an affected child being born to the proband assuming $\frac{?}{\Phi}$ that the upper extremity defect in II.12 was a 340 
manifestation of SF/SH syndrome. The prior probability that the gene was inherited from II.6, given autosomal dominant inheritance, is $0 \cdot 5$. The conditional probability that having inherited the gene it would remain unexpressed in III.5 is $1-y$ (where y is the penetrance of the gene). The posterior probability (P) that III.5 has inherited the gene, given a normal examination, is:

$$
P=\frac{0.5(1-y)}{0.5(1-y)+0 \cdot 5}
$$

The conditional probability of the child of III. 5 being affected is the probability of inheriting the gene multiplied by its penetrance, or $0.5 y$. Overall the chance of an affected child being born is the product of these probabilities:

$$
P=\frac{0.5(1-y)}{0.5(1-y)+0.5} \times 0.5 y .
$$

Algebraic simplification yields:

$$
P=\frac{y-y^{2}}{4-2 y}
$$

Evaluating this for various values of $y$ results in the probabilities shown in the table and represented diagrammatically in fig 2 Regardless of the true value of the penetrance $(y)$ for a given condition, the maximal risk of an affected child is approximately $8.6 \%$ (at a penetrance of about 0.59 ). Similar results can be obtained more elegantly by simple calculus, but the algebraic calculations are presented here for ease of presentation and for general comprehensibility.

A more general derivation of the probability $\mathbf{P}$ of a child being an affected heterozygote for any value of the prior (Mendelian) probability (R) of heterozygosity in a parent is:

$$
\begin{aligned}
\mathbf{P} & =\frac{R-R y}{1-R y} \times 1 / 2 y \\
& =\frac{R\left(y-y^{2}\right)}{2(1-R y)}
\end{aligned}
$$

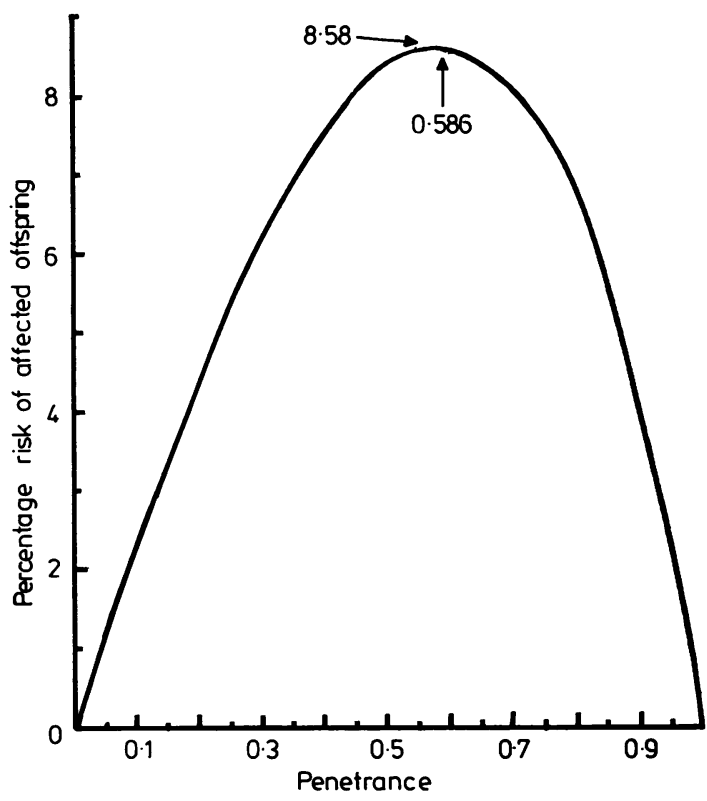

FIG 2 Curve generated by solving equation (3): $P=\frac{y-y^{2}}{4-2 y}$ for values of $y$ between 0 and $1 \cdot 0$.

Penetrance (on the abscissa) is plotted versus the predicted probability of an affected offspring being born to a clinically unaffected subject who is at $50 \%$ genetic risk (on the ordinate). The maximum risk is $8.58 \%$ when the penetrance $(y)$ is 0.586 .

If we denote the complement of $\mathbf{R}$ by $\mathbf{N}$ (for nonreceipt), that is, $N=1-R$, then it can be shown that:

$$
\mathrm{P}_{\max }=\left(\mathrm{N}^{1 / 2}-\mathrm{N}\right)^{2} / 2 \mathrm{RN}
$$

which occurs when the penetrance $(y)$ is $\left(1-N^{1 / 2}\right) / R$.

Then, for example, if the prior probability $(R)$ is 0.25 , as would be the risk of heterozygosity of a consultand who was the grandchild of an affected subject and whose parents cannot be examined, the

\begin{tabular}{|c|c|c|c|c|c|c|c|c|c|c|c|}
\hline \multirow{2}{*}{$\begin{array}{l}\text { A priori probability } \\
(R) \text { of risk }\end{array}$} & \multicolumn{11}{|c|}{ Penetrance $(y)$} \\
\hline & 0 & $0 \cdot 1$ & 0.2 & $0 \cdot 3$ & 0.4 & 0.5 & 0.6 & $0 \cdot 7$ & 0.8 & 0.9 & $1 \cdot 0$ \\
\hline $\begin{array}{l}0.5 \\
0 \cdot 25 \\
0.125\end{array}$ & $\begin{array}{l}\mathbf{0} \\
\mathbf{0} \\
\mathbf{0}\end{array}$ & $\begin{array}{l}0.024^{*} \\
0.012 \\
0.006\end{array}$ & $\begin{array}{l}0.044 \\
0.021 \\
0.010\end{array}$ & $\begin{array}{l}0.062 \\
0.028 \\
0.014\end{array}$ & $\begin{array}{l}0.075 \\
0.033 \\
0.016\end{array}$ & $\begin{array}{l}0.083 \\
0.036 \\
0.017\end{array}$ & $\begin{array}{l}0.086 \\
0.035 \\
0.016\end{array}$ & $\begin{array}{l}0.081 \\
0.032 \\
0.014\end{array}$ & $\begin{array}{l}0.067 \\
0.025 \\
0.011\end{array}$ & $\begin{array}{l}0.041 \\
0.015 \\
0.006\end{array}$ & $\begin{array}{l}\mathbf{0} \\
\mathbf{0} \\
\mathbf{0}\end{array}$ \\
\hline
\end{tabular}
maximal risk for the next generation is $3.59 \%$ at a penetrance of $\mathbf{0 . 5 3 6}$. Various risk values for prior

TABLE Probability of an affected offspring being born to an unaffected subject who is at $50 \%, 25 \%$ or $12 \cdot 5 \%$ risk of being heterozygous at a locus for a rare autosomal dominant disorder for various values of penetrance (y) in the heterozygote

$0.024=2.4 \%$, etc. 
probabilities of 0.25 and 0.125 are listed in the table. Prior probabilities (R) much higher than 0.5 are rarely, if ever, encountered in autosomal dominant inheritance of rare diseases, but, under such conditions, the maximal risk could be higher than $8.6 \%$.

\section{Discussion}

The curve shown in fig 2 is generally applicable in estimating the risk of an affected offspring being born to a subject at an a priori $50 \%$ risk for, but not expressing evidence of, any rare autosomal dominant condition. When the penetrance is known, a precise estimate can be given. In the more frequent situation where penetrance is indeterminate, the maximal value of $8.6 \%$ may be used. Furthermore, this value may be used in cases such as the one presented here, in which it is not certain whether the proband is at risk for the condition but where 'worst possible scenario' risk counselling seems justified.

This risk estimate is applicable only to conditions in which penetrance is constant regardless of age, such as in autosomal dominant isolated congenital malformations or malformation syndromes or in diseases with age dependent penetrance, where the

I

II

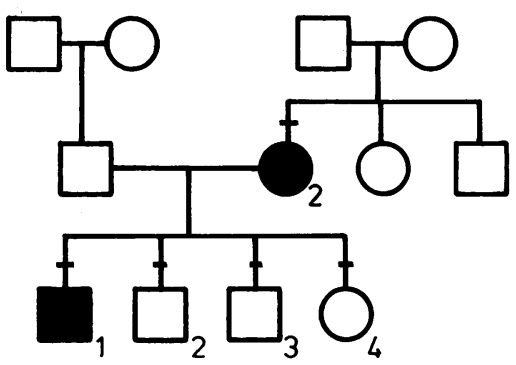

FIG 3 Pedigree of family with dominant ocular coloboma. Patient II.2 has iris colobomata, while subject III.I has" a cystic eye. Bar over the pedigree symbol indicates that the subject was examined, including ophthalmoscopical examination of dilated eyes. proband's age exceeds the age at which constant penetrance is approached. These estimates therefore cannot be used in disorders such as Huntington'so disease or polycystic kidney disease in which듬 penetrance becomes maximal late in life.

This estimate of risk has not previously been $\bar{\varnothing}$ emphasised as being valuable in counselling for diseases with indeterminate penetrance. Precise ${ }^{\infty}$ figures for penetrance are unavailable for most $\vec{\circ}$ autosomal dominant conditions. Many dominant $\overrightarrow{ }$ disorders manifest at birth appear to have reduced $\omega$ penetrance, for example aplasia cutis congenita with $\overline{3}$ distal limb defects, ${ }^{4}$ vanderWoude syndrome, ocular colobomata, ${ }^{6}$ and Pfeiffer syndrome. ${ }^{7}$ Others $\vec{\circ}$ in which penetrance is incomplete and age dependent, 0 such as progressive diaphyseal dysplasia ${ }^{8}$ and ${ }_{+}^{\omega}$ maturity onset diabetes of the young, ${ }^{9}$ may reach maximal penetrance at a relatively early age. In both? groups of disorders the estimate of maximal risk $\vec{\overrightarrow{ }}$ given here may be used. Two illustrative examples are given in figs 3 and 4.

A family requested counselling for ocular吕 coloboma/microphthalmia (fig 3). Autosomal $\vec{\bullet}$ dominant coloboma shows a wide range of expression including isolated chorioretinal or irideal coloboma, cystic eye, microphthalmia, and clinical anoph-o thalmia. ${ }^{10}$ Subject II.2 (fig 3) had typical iris coloboma, while III.1 had a cystic microphthalmicō eye. Given the reduced penetrance in this disease, ${ }^{6}$ theo unaffected children (III.2, III.3, III.4), who had@ completely normal ophthalmological examinations, $\overrightarrow{0}$ maximally have an $8.6 \%$ risk of each of their 3 offspring being affected.

The second family had progressive diaphyseato dysplasia (Camurati-Engelmann disease) and was seen in our clinic. ${ }^{8}$ The pedigree demonstrates theo diminished penetrance of this gene (fig 4): a clearly음 affected man (IV.1) had an unaffected father (III.2) and paternal grandfather (II.1) in a kindred whereo these subjects must be carriers of the mutant gene. $₹$ The risks for affected children being born to six 응 subjects in this kindred (IV.2, IV.3, IV.4, IV.5, IV.6, D IV.11) can be predicted using the rule developed in this article. All these persons have a maximum riskn

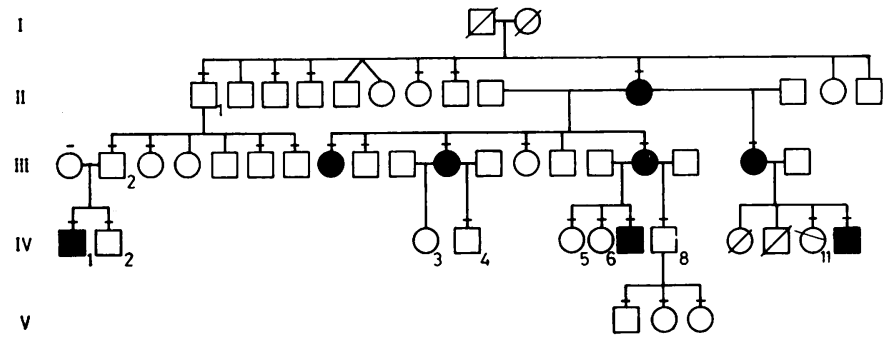

FIG 4 Pedigree of family with progressive diaphyseal dysplasia (modified from Sparkes ${ }^{+}$ and Graham $^{8}$ ). Bar over the symbol indicates that the subject was examined clinically and radiologically. 
of $8.6 \%$ of having children with clinically or radiologically detectable diaphyseal dysplasia.* The risk of clinical disease is indeterminately less than this maximal risk. It would be decreased by the ratio of the two penetrance values (for clinical disease and for radiological manifestation). This ratio is unknown in progressive diaphyseal dysplasia, but is clearly less than one. ${ }^{8}$ The ratio of clinically affected subjects to subjects with radiological evidence of disease is $5 / 8$ in this family. ${ }^{8}$ If this were the true ratio, then the overall risk would be $0.086 \times 5 / 8$, or about $5 \frac{1}{2} \%$.

There are some additional dominant disorders in which it is unclear whether penetrance is complete, and some families occasionally seek counselling who have apparent but previously undescribed autosomal dominant disorders with incomplete penetrance. The maximal risk figure of $8.6 \%$ for an affected child being born to an unaffected proband at $50 \%$ risk for having inherited the gene is applicable for these situations as well.

Supported by fellowship grant GM 06730 and genetics center grant GM 15253 from the National Institutes of Health. We thank Dr Joseph Felsenstein for his help, and Drs E A Murphy and R A Pagon for critical review.

*The risk for IV. 8 would be lower since he had three clinically and radiologically unaffected children. His actual risk of being a carrier therefore is further reduced.

\section{References}

1 Temtamy SA, McKusick VA. The genetics of hand malformations. New York: Liss, 1978: 53-72.

2 Vogel F. Verzögerte Mutation beim Menschen? Einige kritische Bemerkungen zu Ch. Auerbachs Arbeit. Ann Hum Genet 1958; 22: 132-7.

3 Scott W. Syndactylism with variations. J Hered 1933; 24: 241-3.

${ }^{4}$ Scribanu N, Temtamy SA. The syndrome of aplasia cutis congenita with terminal transverse defects of limbs. J Pediatr 1975; 87:79-82.

5 vanderWoude A. Fistula labii inferioris congenita and its association with cleft lip and palate. Am J Hum Genet $1954 ; 6: 244-56$.

${ }^{6}$ Bell J. On some hereditary structural anomalies of the eye and on the inheritance of glaucoma. In: Pearson K, ed. The treasury of human inheritance. Vol II, part 5. London: Cambridge University Press, 1932: 427-77 + plates LXX-LXXII.

7 Robinow M, Sorauf TJ. Acrocephalopolysyndactyly, type Noack, in a large kindred. Birth Defects 1975; XI, No 5; 99-106.

${ }^{8}$ Sparkes RS, Graham CB. Camurati-Engelmann disease. Genetics and clinical manifestations with a review of the literature. J Med Genet 1972; 9: 73-85.

9 Tattersall RB. Mild familial diabetes with dominant inheritance. $Q J$ Med 1974; 43: 339-57

${ }^{10}$ Pagon RA. Ocular coloboma. Surv Ophthalmol (in press).

Requests for reprints to Professor A G Motulsky, Center for Inherited Diseases, RG-20, University of Washington, Seattle, Washington 98195, USA.

\section{Note added in proof}

After this manuscript was accepted, an article has come to our attention (Aylesworth AS, Kirkman NH. Birth Defects 1979; XV, No 5C: 25-38) which details Bayesian calculations for genetic counselling in similar and additional situations involving incomplete penetrance of autosomal dominant disorders. 